\section{US nuclear snag}

President Carter's plans to defer nuclear fuel reprocessing and to turn down the breeder reactor programme have hit a snag in the US House of Representatives and they could face a stiff challenge in the Senate. Last week, the House Committee on Science and Technology voted 38 to 0 to keep funds for a demonstration breeder reactor in the budget for the Energy Research and Development Administration (ERDA), but with the understanding that the committee will investigate the matter further and vote on the funds again before sending the ERDA budget bill to the House floor.

ThE heavy veils of secrecy that the French are drawing over the details of their method of enriching uranium to reactor- but not to weaponsgrade make it difficult to evaluate their claims. But if their recently revealed chemical enrichment technique stands up to full scale testing and is as tamper-proof as they suggest, cheap enrichment plant should be available in the 1990 s to many countries which might not have been considered responsible enough to own it.

The French announcement, at the recent IAEA nuclear fuel cycle conference in Salzburg, was neatly timed to coincide with the economic summit in London. With an undoubted shortage of enrichment plants the new process seems to offer the possibility of meeting the need without increasing the risk of proliferation. It is not clear, however, whether such enrichment facilities would allow the use of the fast breeder reactor to be postponed; that depends on whether, in the absence of the new technique, the use of uranium in thermal reactors would be limited by a shortage of enrichment facilities or by the scarcity of uranium itself-which in turn will be determined by the economics of extraction.

Enrichment used to receive a great deal of attention as a process encouraging nuclear proliferation. Concern has since focused on reprocessing the spent fuel. Natural uranium, containing $99.3 \%{ }^{238} \mathrm{U}$ and $0.7 \%$ fissile ${ }^{235} \mathrm{U}$, must be enriched to $3-4 \%{ }^{233} U$ for use in American LWRs and $2 \%$ for the British AGRs. The Canadian CANDU and the British Magnox reactors use natural uranium, as oxide and metal respectively. The sensitive aspect of enrichment is that an enrichment plant may be arranged so that enrichment to over $90 \%$ instead of $2-4 \%$ is

Committee sources note that the vote was a procedural measure which doesn't necessarily indicate the committee's final view, though they suggest that the prevailing opinion among committee members seems at present to favour rejecting Carter's request to cancel the demonstration project. In the Senate, Senator Frank Church, who heads a key energy subcommittee, said in a speech at MIT earlier this month that Carter's plutonium strategy will not work because other countries are unlikely to follow suit. In a later interview with the Washington Post, Church said that the United States should continue with the breeder project and with reprocessing to avoid

achieved, enough to make a uranium bomb.

Reprocessing offers a similar opportunity, but here to make a plutonium bomb. The civil purpose of reprocessing spent reactor fuel-that is, separating plutonium from uranium and radioactive wastes-is to use the

\title{
Power sans bombs
}

\section{Sorry, for copyright reasons some images on this page may not be available online}

\section{BACKGROUNDER}

plutonium to fuel more reactors and especially the fast breeder. The French development could make it more difficult to get hold of uranium bombs, but would not affect the ease of access to plutonium bombs.

The main enrichment process in current use is gaseous diffusion, uranium hexafluoride being diffused through a porous membrane. The lighter ${ }^{235} \mathrm{U}$ atoms diffuse slightly more readily than the ${ }^{238} \mathrm{U}$ and enrichment is achieved by a large number of stages in cascade. Compression and cooling at each stage mean that energy consumption is very high $(6 \%$ of the energy generated by PWR fuel). In the newer ultracentrifugation process, favoured by the British, Germans and Dutch, the "nuclear isolationism". The opposition to Carter's plans virtually guarantees that there will be a major debate on plutonium policy on the floor of the House and the Senate this summer.

\section{Pipeline report}

Controversial recommendations from a Canadian judge regarding proposed pipelines stretching between the Arctic and Southern Canada and the USA will not be acted upon at least until a second report is published, probably in the summer. The judge, Thomas Berger, reported on the ecological and social implications of the proposal last week, and recommended a morator-

diffuser is replaced by a centrifuge. The capital costs of centrifugation are very high but the electricity consumption is only $10 \%$ that of diffusion.

The chemical exchange process announced by the French is said to have the advantages of low energy consumption, rather simple technology and suitability for small-scale plants. Separation of the two uranium isotopes based on the different rates with which molecules containing them react has been explored in the past, but had been largely discounted by most workers because the very small difference in chemical reaction rate only allows extremely slow separation.

The French breakthrough apparently lies in finding two uranium compounds which undergo reactions whose rates are more markedly affected by the uranium isotope. What the molecules are has not been revealed. The enrichment process is still rather slow but this is the main safeguard against bomb manufacture; while the period of two years needed to produce $3 \%$ enriched uranium by the chemical method seems industrially feasible, it would take fully 30 years to produce bomb-grade plutonium. By contrast, bomb-grade material can be prepared in two years by gaseous diffusion and one day by ultracentrifugation.

The French say two other safeguards are built into their process. One is that the process cannot be arranged in cascades (which can, at least in theory, be manipulated to produce a small quantity of $90 \%$ enriched fuel instead of a larger quantity of $3 \%$ enriched fuel). Furthermore, if too much enrichment is attempted, the uranium risks going critical. This seems to be because a liquid phase is involved, and in a liquid there is the risk of local concentrations of very high enrichment. 
ium, to the chagrin of industrial interests. A second report on the economic need for the pipeline is awaited from the Canadian National Energy Board, which regulates the oil and gas industries and is still holding hearings.

\section{USSR action on seminar}

Professor Mark Azbel has been ordered by the Soviet authorities to cease holding the 'Sunday Seminars' for refusnik scientists. The seminars have been held regularly for five years, and only a month ago Professor Azbel was given a once-off permission to hold a special anniversary session-the first time that the authorities openly acknowledged the existence of the seminars.

Within the past three weeks, Pro- fessor Azbel has been summoned three times to the Lubyanka and Lefortovo prisons for interrogation. $\mathrm{He}$ was obliged to sign an undertaking not to reveal the contents of the investigation. It is known, however, that it related to his association with Anatolii Shcharanskii, the unofficial 'press-agent' of the seminar group at present held for investigation for alleged contact with the CIA.

Last week Dr Viktor Brailovskii and Dr Veniamin Fain, who are among the senior members of the group, were also called in for interrogation.

The most recent message received from Professor Azbel was that the authorities are striking at the 'Professorate'. Previous action against refusnik scientists has been aimed at the lower echelons.

\section{NPL's new director}

Dr Paul Dean is to take over as director of the National Physical Laboratory (NPL) on 1 October. $\mathrm{He}$ will succeed Sir Iuean Maddock, who has been acting director since giving up his appointment as chief scientist at the Department of Industry at the end of last March. Dr John Dunworth, the previous permanent director, retired last June; he joined the NPL as deputy director in 1962 and became responsible for the laboratory in 1964. Dean joined the laboratory in 1957, and will be moving from the Department of Industry's headquarters, where he was head of the Space and Air Research division. He was also Head of the Research and Development Contractors division.
They came in busloads from as far away as Minnesota. They wore prolaetrile buttons. They were prepared to pack the hearing room, to applaud wildly at the inflammatory oratory of their leaders, and to boo, hiss and interrupt when members of the 'medical establishment' warned them of the uselessness of laetrile in cancer therapy.

The occasion was the Food and Drug Administration (FDA) Administrative Rulemaking Hearing on Laetrile, held in Kansas City, Missouri at the beginning of May. To 'bend over backwards', the FDA had talks by the laetrile crusaders, following opening remarks by the presiding officer. My experience with hearings led me to know that the television cameras and reporters would be present at the morning session, and they would depart at noon, leaving the opponents of laetrile without media coverage, just as the opponents of banning DDT were treated in 1969.

Efforts at appeasement always fail. At 8 am on the first day the laetrile pushers called a press conference that was largely devoted to rhetoric against the FDA and allegations that the hearings were a "kangaroo court". I asked if the laetrile supporters had been given the opportunity to speak at the hearings. The answer was, necessarily, "yes", but a woman hastened to my side and hissed in my ear that if I interrupted their press conference with any more questions, she would call the hotel manager and have me removed forcibly from the room. I managed to avoid this fate when I asked my next question, by alleging that I was a reporter for Nature. I requested any scientific literature reference, even one, to substantiate the claim that laetrile is vitamin B17. I was told "wait until tomorrow".

During the hearings, professors of medicine were jeered at and heckled. Advocates of laetrile, shouting and declaiming in the manner of a

\section{Quackery triumph}

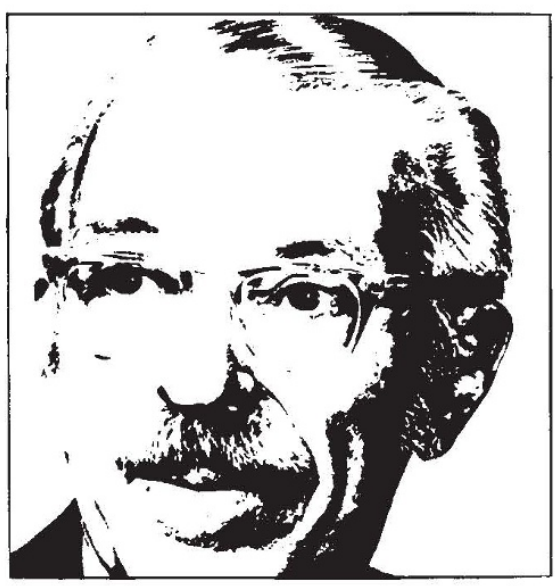

\section{THOMAS H. JUKES}

religious revival meeting, were wildly applauded as they testified to their "cures". The audience was ecstatic, as well it might be. Bills to legalise laetrile without even defining what laetrile actually is, have just been passed by the legislatures of Alaska, Florida, Indiana and Nevada. The Indiana Bill had successfully overridden the Governor's veto. The Nevada bill includes a $10 \%$ cut on laetrile sale for the State Treasury.

The publication of the laetrile pushers, The Choice, was bursting with exultant information. It contained advertisements for "Reverend Clifford Oden's stirring call to faith in God and vitamin B17", for a new water distiller that would remove fluoride from drinking water, and for a book on "chelation therapy in the killer diseases". The publication informed its readers that "efforts to decriminalise laetrile use in Texas surged into the forefront where 150 members of the lower house shouted their approval of the freedom of choice bill and stood up and cheered after the unanimous vote was delivered". One of the photographs showed two 'Wisconsin committee leaders' carrying ' 23,000 names on signatures" in support of pro-laetrile bills introduced into the Wisconsin legislature; another was of Glo-ia Swanson telling her health philosophy and her personal victory over a tumour.

The pro-laetrile campaign is administering a crushing defeat to science and rationality. Undoubtedly it is well-financed. A Californian 'laetrile physician' was indicted on charges including one of depositing $\$ 2,500,000$ in California banks, May 1973 to August 1975. His licence was revoked for "gross negligence and incompetence", 29 November, 1976.

The technique for arousing suppont is an appeal to revolt against authority, bureaucracy and the "medical establishment'. Political action is effected by writing letters to legislaitors. This procedure was overwhelmingly successful with the Proxmire Bill in the US Senate 1975, specifically directed against the authority of the FDA.

Things fall apart; the centre cannot hold; Mere anarchy is loosed upon the world,

The blood-dimmed tide is loosed, and everywhere

The ceremony of innocence is doomed;

The best lack all conviction, while the worst

Are full of passionate intensity.

W. B. Yeats 